\title{
Healthy Lifestyle Habits and Mortality in Overweight and Obese Individuals
}

\author{
Eric M. Matheson, MS, MD, Dana E. King, MS, MD, and Charles J. Everett, PhD
}

Background: Though the benefits of healthy lifestyle choices are well-established among the general population, less is known about how developing and adhering to healthy lifestyle habits benefits obese versus normal weight or overweight individuals. The purpose of this study was to determine the association between healthy lifestyle habits (eating 5 or more fruits and vegetables daily, exercising regularly, consuming alcohol in moderation, and not smoking) and mortality in a large, population-based sample stratified by body mass index (BMI).

Methods: We examined the association between healthy lifestyle habits and mortality in a sample of 11,761 men and women from the National Health and Nutrition Examination Survey III; subjects were ages 21 and older and fell at various points along the BMI scale, from normal weight to obese. Subjects were enrolled between October 1988 and October 1994 and were followed for an average of 170 months.

Results: After multivariable adjustment for age, sex, race, education, and marital status, the hazard ratios (95\% CIs) for all-cause mortality for individuals who adhered to $0,1,2$, or 3 healthy habits were $3.27(2.36-4.54), 2.59(2.06-3.25), 1.74(1.51-2.02)$, and $1.29(1.09-1.53)$, respectively, relative to individuals who adhered to all 4 healthy habits. When stratified into normal weight, overweight, and obese groups, all groups benefited from the adoption of healthy habits, with the greatest benefit seen within the obese group.

Conclusions: Healthy lifestyle habits are associated with a significant decrease in mortality regardless of baseline body mass index. (J Am Board Fam Med 2012;25:9-15.)

Keywords: Alcohol Use, Exercise, Nutrition, Obesity, Tobacco Use Cessation

In an effort to reduce premature morbidity and mortality, public health officials and health care providers have stressed the critical importance of adherence to a healthy lifestyle that includes exercising regularly, eating a diet high in fruits and

This article was externally peer reviewed.

Submitted 3 May 2011; revised 26 August 2011; accepted 2 September 2011.

From the Department of Family Medicine, Medical University of South Carolina, Charleston.

Funding: none.

Conflict of interest: none declared.

Disclaimer: All authors had access to the data and a role in writing this manuscript. The National Health and Nutrition Examination Survey (NHANES) is conducted and supported by the National Center for Health Statistics (NCHS), which is part of the Centers for Disease Control and Prevention (CDC). This manuscript was prepared using the NHANES public use dataset and does not necessarily reflect the opinions or views of the NCHS or CDC.

Corresponding author: Eric M. Matheson, Department of Family Medicine, Medical University of South Carolina, 295 Calhoun Street, Charleston, SC 29425 (E-mail: Matheson@musc.edu). vegetables, avoiding or quitting smoking, and consuming alcohol in moderation. Though the benefits of healthy lifestyle choices are well established among the general population, less is known about the relative benefit of healthy habits among obese versus normal weight and overweight individuals. ${ }^{1,2}$

A large body of epidemiologic evidence suggests that obesity is an independent risk factor for early mortality. ${ }^{3,4}$ Though the evidence for the risk of being overweight is mixed, most studies find no increased risk of mortality among overweight people. ${ }^{3-5}$ The increased risk of mortality associated with obesity is of considerable concern because more than $33 \%$ of American adults are categorized as obese (body mass index $[\mathrm{BMI}] \geq 30$ ). ${ }^{6}$ By even the most conservative estimates, obesity is responsible for more than 80,000 deaths annually. ${ }^{3}$ Obesity increases the risk of illnesses such as coronary artery disease, diabetes mellitus, hypertension, sleep 
apnea, and several types of cancer. ${ }^{7,8}$ In addition to increasing morbidity and mortality, obesity is a major financial strain on both individuals and society, with the direct annual medical costs estimated to be in excess of $\$ 147$ billion dollars. 9

Fortunately, regardless of an individual's BMI, adherence to healthy lifestyle habits seems to decrease the risk of premature mortality. ${ }^{1,10,11}$ These findings may be of particular importance given that fewer than 1 in 5 Americans who attempt to lose weight are successful in maintaining weight loss over time. ${ }^{12,13}$

The purpose of this study was to determine the association between healthy lifestyle habits (consumption of $\geq 5$ servings of fruits or vegetable/day, regular exercise $>12$ times per month, moderate alcohol consumption [up to 1 drink per day for women and up to 2 drinks per day for men], and not smoking) and all-cause mortality in US adults 21 years of age and older. The study focuses on this age range of the adult population because alcohol consumption is illegal in the United States among individuals younger than 21 years of age.

\section{Methods}

This study was reviewed by the institutional review board of the Medical University of South Carolina and was found to be exempt.

\section{Dataset}

The National Health and Nutrition Examination Survey (NHANES) III is a nationally representative survey based on a complex sampling design that allows for weighted population estimates of the noninstitutionalized US population. The NHANES III was conducted in the United States between October 1988 and October 1994 by the National Center for Health Statistics. The sample was composed of approximately 40,000 noninstitutionalized US civilians, with a lower age limit of 2 months and no upper age limit. The survey included a physical examination, numerous laboratory studies, and an extensive questionnaire about lifestyle, diet, and medical history. The NHANES III survey and sampling procedure has been described previously in the literature. ${ }^{14}$

\section{Definitions of Obesity, Overweight, and Normal Weight}

For the purposes of this study, obesity was defined as a $\mathrm{BMI} \geq 30$, overweight as a $\mathrm{BMI} \geq 25$ and $<30$, and normal weight as a $\mathrm{BMI} \geq 18.5$ and $<25$, according to the definition provided by the National Institutes of Health. ${ }^{15}$ BMI was determined by taking actual measurements of the height and weight of participants then computing BMI based on weight $(\mathrm{kg})$ divided by height $\left(\mathrm{m}^{2}\right)$.

\section{Healthy Lifestyle Factors}

Smoking status was determined by self-report of whether the individual currently smoked cigarettes, pipes, or cigars. Intake of at least 5 servings of fruits and vegetables a day was obtained by using the healthy eating index dataset, which contains data on the number of servings of food consumed by survey participants. Level of physical activity was determined according to the frequency of participation in leisure-time physical activities within the previous month. These activities included walking, jogging or running, riding a bicycle or exercise bicycle, swimming, aerobic exercise, aerobic dancing, regular dancing, calisthenics, garden or yard work, weightlifting, or other similar activities. ${ }^{16}$ The average time spent exercising and level of intensity of participants' exercise were not analyzed. Physical activity was divided into 2 frequency groups ( $0-12$ and $>12$ times per month), a division consistent with national recommendations at the time of the NHANES III. ${ }^{17}$ Moderate alcohol consumption was defined as more than 0 but no more than 1 drink a day for women and up to 2 drinks a day for men, according to current guidelines of the US Department of Agriculture. ${ }^{18}$ To be consistent with previous studies, the 4 healthy habits were defined as engaging in physical activity $>12$ times a month, being a nonsmoker, consuming $\geq 5$ servings of fruit and vegetables a day, and drinking alcohol in moderation. ${ }^{19,13}$

\section{Mortality}

The NHANES III Mortality Study was a prospective cohort study comprised of individuals 17 years of age and older at the time of study enrollment. Deaths were determined by linking information from the National Death Index to matching personal identifiers in the NHANES III. Participants were followed from the time of study enrollment through December 31, 2006.

\section{Demographic Variables}

Demographic variables (age, sex, race, education, and marital status) were included as control vari- 
ables because of their known impact on healthy habits. ${ }^{1,20}$ Age was treated as a continuous variable. Sex was categorized as either female or male. Race included three categories: non-Hispanic white, non-Hispanic black, and Hispanic. Marital status was dichotomized into married or living with a partner and nonmarried. Education was categorized by years of education completed as follows: 0 to 11 years, 12 years, 12 to 16 years, and $\geq 17$ years.

\section{Statistical Analysis}

To account for the complex sample design used in the NHANES, SUDAAN software (RTI International, Research Triangle Park, NC) was used for all analyses. The analyses incorporated both the stratification and clustering aspects of the sampling design. The proper weighting procedures included adjustments for basic probability of selection and adjustments for nonresponse. Because minorities were oversampled and the sampling design was complex, sampling weights provided in the NHANES public use dataset were used to compute population estimates based on weighted parameter estimates and standard errors.

Descriptive statistics for the sample stratified by BMI were computed (Table 1). A Cox proportional hazard ratio then was calculated for the entire sample, comparing the risk of all-cause mortality for individuals who adhered to $0,1,2$, or 3 healthy habits versus individuals who adhered to all 4 healthy habits, controlling for age, race, and sex (Table 2). A survival analysis stratified by BMI then was performed using normal-weight individuals who adhered to all 4 healthy habits as the reference group (Table 3). Finally, a survival analysis was performed, examining each individual healthy habit (ie, engaging in physical activity, not smoking, consuming $\geq 5$ fruits or vegetables daily, and drinking alcohol in moderation). All individuals were included in this analysis (Table 4). The proportionality assumption was tested for all survival analyses using Schoenfeld residuals. A Wald test also was performed to determine whether an interaction existed between healthy habits and BMI. No interaction between these was found, with $P$ ranging between .1 and .9.

\section{Results}

Using the inclusion criteria outlined in the Methods section, the unweighted sample of participants
Table 1. Demographic Characteristics of Study Sample Obtained from NHANES III Survey*

\begin{tabular}{|c|c|c|c|c|}
\hline & \multicolumn{4}{|c|}{ Body Mass Index } \\
\hline & $18.5-24.9$ & $25-29.9$ & $\geq 30$ & Total \\
\hline \multicolumn{5}{|l|}{ Age (years) } \\
\hline $21-44$ & 65.9 & 53.8 & 53.2 & 59.0 \\
\hline $45-64$ & 21.4 & 29.7 & 33.0 & 26.7 \\
\hline$\geq 65$ & 12.7 & 16.4 & 13.8 & 14.2 \\
\hline \multicolumn{5}{|l|}{ Race } \\
\hline Non-Hispanic white & 83.6 & 79.4 & 75.4 & 80.3 \\
\hline Non-Hispanic black & 8.7 & 9.9 & 13.7 & 10.2 \\
\hline Hispanic & 7.7 & 10.7 & 10.9 & 9.4 \\
\hline \multicolumn{5}{|l|}{ Sex } \\
\hline Female & 56.4 & 40.5 & 58.2 & 51.4 \\
\hline Male & 43.6 & 59.5 & 41.8 & 48.6 \\
\hline \multicolumn{5}{|l|}{ Education level } \\
\hline Less than high school & 19.6 & 23.4 & 25.6 & 22.2 \\
\hline High school & 33.1 & 34.5 & 38.7 & 34.8 \\
\hline Some college & 35.9 & 32.1 & 29.4 & 33.2 \\
\hline College or greater & 11.5 & 9.9 & 6.3 & 9.8 \\
\hline \multicolumn{5}{|l|}{ Marital status } \\
\hline Married or partner & 63.9 & 71.7 & 70.0 & 67.9 \\
\hline Living alone & 36.1 & 28.3 & 30.1 & 32.1 \\
\hline \multicolumn{5}{|l|}{ Exercise frequency } \\
\hline None & 11.5 & 12.4 & 16.2 & 12.8 \\
\hline $1-12$ times per month & 30.0 & 31.4 & 36.5 & 31.9 \\
\hline$>12$ times per month & 46.6 & 34.6 & 18.8 & 55.3 \\
\hline \multicolumn{5}{|l|}{ Smoking status } \\
\hline Current nonsmoker & 65.9 & 71.7 & 75.7 & 70.0 \\
\hline Current smoker & 34.1 & 28.3 & 24.3 & 30.0 \\
\hline \multicolumn{5}{|l|}{ Fruit/vegetables } \\
\hline$<5$ servings/day & 61.7 & 58.6 & 64.5 & 61.3 \\
\hline$\geq 5$ servings/day & 38.3 & 41.4 & 35.5 & 38.7 \\
\hline \multicolumn{5}{|l|}{ Alcohol consumption } \\
\hline None & 36.8 & 42.3 & 53.4 & 42.3 \\
\hline Moderate & 52.2 & 48.9 & 39.3 & 48.2 \\
\hline Exceeds moderate & 11.0 & 8.8 & 7.3 & 11.0 \\
\hline \multicolumn{5}{|l|}{ Healthy habits (\%) } \\
\hline None & 2.8 & 1.6 & 1.5 & 2.0 \\
\hline 1 & 13.8 & 11.7 & 12.0 & 12.7 \\
\hline 2 & 31.0 & 30.8 & 36.7 & 32.2 \\
\hline 3 & 33.5 & 36.5 & 33.6 & 34.6 \\
\hline 4 & 18.9 & 19.4 & 16.2 & 18.5 \\
\hline
\end{tabular}

${ }^{*}$ Sample size $=11,761$ unweighted $(133,700,723$ weighted $)$.

included a total of 11,761 individuals, which was equivalent to a weighted sample size of $133,700,723$. Subjects were enrolled between October 1988 and October 1994 and were followed for an average of 170 months. A total of 2281 individuals (weighted, $\mathrm{N}=18,437,659$ ) died during the follow-up period. 
Table 2. Cox Proportional Hazards Models for Risk of All-Cause Mortality for All Individuals Ages 21 and Older by Adherence to $0,1,2,3$, or 4 Healthy Habits* Sample size $=11,761$ unweighted $(133,700,723$ weighted)

\begin{tabular}{ccc}
\hline $\begin{array}{c}\text { Number of } \\
\text { Healthy Habits }\end{array}$ & Hazard Ratio & $\begin{array}{c}\text { 95\% Confidence } \\
\text { Interval }\end{array}$ \\
\hline 0 & 3.27 & $2.36-4.54$ \\
1 & 2.59 & $2.06-3.25$ \\
2 & 1.74 & $1.51-2.02$ \\
3 & 1.29 & $1.09-1.53$ \\
4 & 1.00 & - \\
\hline
\end{tabular}

*Adjusted for age, sex, race, education, and marital status. Healthy habits include consumption of $\geq 5$ fruits or vegetable/ day, regular exercise $>12$ times/month, moderate alcohol consumption (up to $1 \mathrm{drink} /$ day for women, up to $2 /$ day for men), and not smoking.

After multivariable adjustment for age, sex, race, education, and marital status, the hazard ratios (95\% CIs) for all-cause mortality for individuals who adhered to $0,1,2$, or 3 healthy habits was 3.27 (2.36-4.54), 2.59 (2.06-3.25), 1.74 (1.51-2.02), and $1.29(1.09-1.53)$, respectively, relative to individuals who adhered to all 4 healthy habits (Table $2)$. When a stratified survival analysis of the entire group was performed, with normal-weight individuals who reported adherence to all 4 healthy habits serving as the reference group, survival improved each time a new healthy habit was added in the overweight and obese groups (Table 3) (Figure 1).

In a survival analysis of individual healthy habits stratified by BMI (Table 4), smoking was associated with increased mortality regardless of baseline weight. Consumption of $\geq 5$ servings of fruits and vegetables was associated with decreased mortality in normal-weight and overweight individuals but not in obese individuals. Regular exercise was associated with decreased mortality in normal-weight and obese individuals but failed to reach statistical significance in overweight individuals. Moderate alcohol consumption was associated with decreased mortality only in normal-weight individuals. The proportionality assumption was tested for all survival analyses using Schoenfeld residuals, which indicated that the proportional assumption was upheld.

\section{Discussion}

The results of this study reinforce the association between healthy lifestyle habits and decreased mor- tality risk regardless of baseline BMI. This finding is of great importance to both patients and health care providers, whose perceptions about BMI may lead them to believe only obese and/or overweight patients require regular counseling about lifestyle adjustments. Although the evidence suggests that patients across the BMI spectrum should adhere to a healthy lifestyle to optimize health, many patients with a normal-weight BMI may believe exercise and healthy eating, for example, are less important for them as long as they maintain a low BMI. ${ }^{1,21,22}$ In fact, this patient view may be reinforced by health care providers who also are influenced by $\mathrm{BMI}$ and are, therefore, significantly more likely to counsel obese patients regarding a healthy lifestyle than normal-weight patients. ${ }^{1,22,23}$

The lack of time spent counseling patients to adopt a healthy lifestyle is reason for concern, and research suggests that this failure to counsel about healthy behaviors is common. For example, one

Table 3. Cox Proportional Hazards Models for Risk of All-Cause Mortality for All Adults Ages 21 and Older by Adherence to 0, 1, 2, 3, or 4 Healthy Habits Stratified by Body Mass Index*

\begin{tabular}{lcc}
\hline $\begin{array}{l}\text { Number of } \\
\text { Healthy Habits }\end{array}$ & Hazard Ratio & $\begin{array}{c}95 \% \text { Confidence } \\
\text { Interval }\end{array}$ \\
\hline $\mathrm{BMI} \geq 18.5$ to $<25$ & & \\
0 & 2.18 & $1.25-3.81$ \\
1 & 2.70 & $1.90-3.83$ \\
2 & 2.11 & $1.57-2.83$ \\
3 & 1.39 & $1.07-1.82$ \\
4 & Reference group & - \\
$\mathrm{BMI} \geq 25$ to $<30$ & & \\
0 & 3.72 & $1.53-9.07$ \\
1 & 2.45 & $1.65-3.67$ \\
2 & 1.63 & $1.29-2.05$ \\
3 & 1.16 & $0.89-1.52$ \\
4 & 1.08 & $0.81-1.46$ \\
$\mathrm{BMI} \geq 30$ & & \\
0 & 6.69 & $3.67-12.2$ \\
1 & 3.26 & $2.03-5.24$ \\
2 & 1.76 & $1.34-2.30$ \\
3 & 1.65 & $1.12-2.42$ \\
4 & 1.05 & $0.66-1.67$ \\
\hline
\end{tabular}

*Sample size $=11,761$ unweighted $(133,700,723$ weighted $)$. Adjusted for age, sex, race, education, and marital status. Healthy habits include consumption of $\geq 5$ fruits or vegetable/ day, regular exercise $>12$ times/month, moderate alcohol consumption (up to $1 \mathrm{drink} /$ day for women, up to $2 /$ day for men), and not smoking.

BMI, body mass index. 
Table 4. Cox Proportional Hazards Models for the Risk of All-Cause Mortality by Individual Habits for All Adults Ages 21 and Older Stratified by Body Mass Index*

\begin{tabular}{|c|c|c|c|}
\hline \multirow[b]{2}{*}{ Individual Healthy Habit } & \multicolumn{3}{|c|}{ Body Mass Index } \\
\hline & $18.5-24.9$ & $25-29.9$ & $\geq 30$ \\
\hline \multicolumn{4}{|l|}{ Current smoker } \\
\hline Yes & $1.69(1.36-2.10)$ & $1.95(1.50-2.55)$ & $1.92(1.38-2.69)$ \\
\hline No & 1.00 & 1.00 & 1.00 \\
\hline \multicolumn{4}{|c|}{ Fruit/vegetable servings per day } \\
\hline$<5$ & 1.00 & 1.00 & 1.00 \\
\hline$\geq 5$ & $0.75(0.61-0.93)$ & $0.83(0.70-0.98)$ & $0.93(0.67-1.30)$ \\
\hline None & 1.00 & 1.00 & 1.00 \\
\hline \multicolumn{4}{|c|}{ Regular exercise (times per month) } \\
\hline $1-12$ & $0.57(0.45-0.72)$ & $0.92(0.71-1.20)$ & $0.70(0.52-0.94)$ \\
\hline$>12$ & $0.59(0.45-0.78)$ & $0.81(0.64-1.02)$ & $0.67(0.47-0.95)$ \\
\hline None & 1.00 & 1.00 & 1.00 \\
\hline \multicolumn{4}{|l|}{ Alcohol consumption } \\
\hline Moderate & $0.78(0.63-0.96)$ & $0.85(0.67-1.08)$ & $0.83(0.58-1.18)$ \\
\hline Exceeds moderate & $0.92(0.65-1.30)$ & $0.99(0.69-1.43)$ & $1.75(1.12-2.74)$ \\
\hline
\end{tabular}

Values provided as hazard ratio $(95 \% \mathrm{CI})$.

*Sample size $=11,761$ unweighted $(133,700,723$ weighted $)$. Adjusted for age, sex, race, education, marital status, and the other healthy habits.

study found primary care providers spent minimal time addressing nutrition ( $2.7 \%$ of total time), exercise ( $2.0 \%$ of time), or smoking ( $1.3 \%$ of time) ${ }^{24}$ Such a lack of focus on counseling is particularly troubling because counseling has been shown to be effective in decreasing smoking, increasing fruit and vegetable consumption, moderating alcohol consumption, and increasing exercise frequency. ${ }^{25-28}$ In the pooled analysis that included all individuals in the cohort (normal weight, overweight, and obese), the adoption of each additional healthy habit decreased all-cause mortality between $29 \%$ and $85 \%$ (Table 2). To put this in perspective, statins decrease all-cause mortality by $12 \%$ in in-

Figure 1. Hazard ratio for all-cause mortality by body mass index $(\mathrm{kg} / \mathrm{m} 2)$ and number of healthy habits (ie, fruits and vegetable intake, tobacco, exercise, alcohol). Data from Table 3.

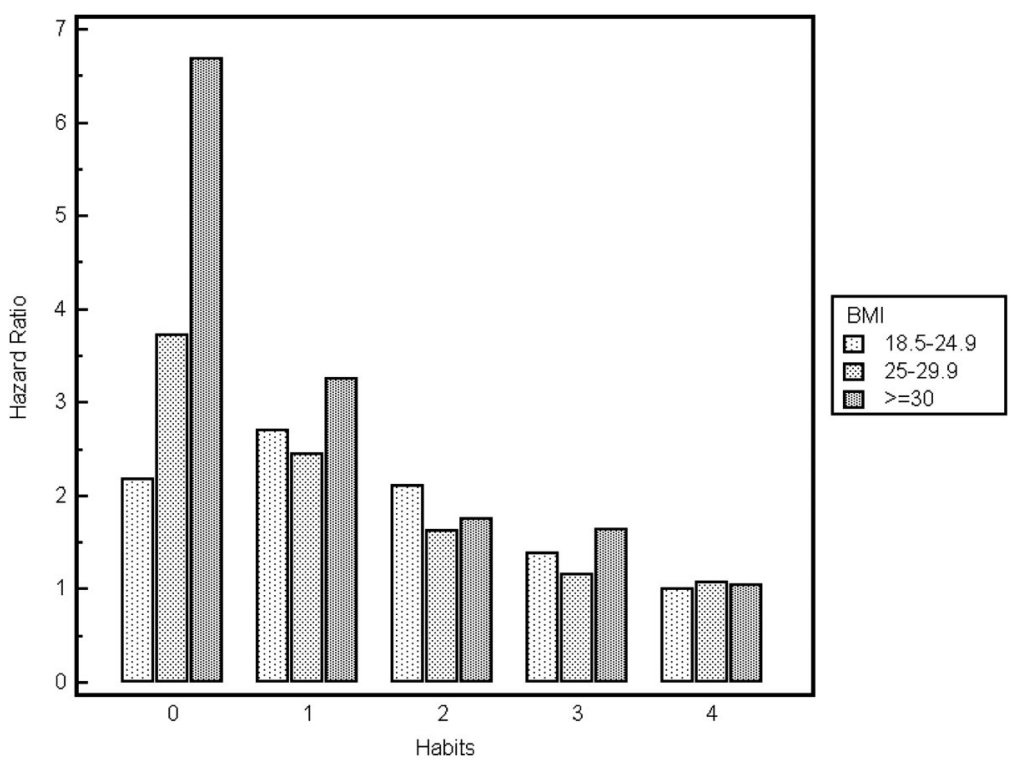


dividuals at high risk for cardiovascular disease. ${ }^{29}$ Given the tremendous benefits of a healthy lifestyle, policies and programs that encourage adherence to healthy lifestyles should be encouraged both locally and at a national level.

This study has several important strengths and weaknesses. The major strengths include the complex sampling design of the NHANES, which makes the findings generalizable to the population of the United States at large, and the accuracy of the National Death Index at assessing mortality. ${ }^{30,14}$ The study also has several noteworthy weaknesses. First, the cross-sectional nature of the interview portion of the survey did not account for changes in lifestyle habits over time. This may be considered a limitation even though lifestyle habits seem to be relatively stable in adulthood. ${ }^{31,32}$ Second, the survey was dependent on the accuracy of selfreport of healthy habits. Third, although healthy habits were associated with decreased mortality, association does not prove causation. Finally, control variables were limited to age, race, and sex in the survival analysis because of uncertainty about how lifestyle interacted with other commonly used control variables such as socioeconomics or marriage.

\section{Conclusion}

Overall, the study reinforces previous findings about the critical importance of adhering to healthy habits. Future studies might focus on effective ways to increase adherence to healthy habits and the cost-effectiveness of such efforts.

\section{References}

1. Khaw KT, Wareham N, Bingham S, Welch A, Luben R, Day N. Combined impact of health behaviours and mortality in men and women: the EPICNorfolk prospective population study. PLoS Med 2008;5:e12.

2. van Dam RM, Li, Spiegelman D, Franco OH, Hu FB. Combined impact of lifestyle factors on mortality: prospective cohort study in US women. BMJ 2008;337:a1440.

3. McGee DL. Diverse Populations Collaboration. Body mass index and mortality: a meta-analysis based on person-level data from twenty-six observational studies. Ann Epidemiol 2005;15(2):87-97.

4. Adams KF, Schatzkin A, Harris TB, et al. Overweight, obesity, and mortality in a large prospective cohort of persons 50 to 71 years old. N Engl J Med 2006;355(8):763-78.

5. Flegal KM, Graubard BI, Williamson DF, Gail MH. Cause-specific excess deaths associated with under- weight, overweight, and obesity. JAMA 2007; 298(17):2028-37.

6. Flegal KM, Carroll MD, Ogden CL, Curtin LR. Prevalence and trends in obesity among US adults, 1999-2008. JAMA 2010;303(3):235-41.

7. Flegal KM, Graubard BI, Williamson DF, Gail MH. Sources of differences in estimates of obesity-associated deaths from first National Health and Nutrition Examination Survey (NHANES I) hazard ratios. Am J Clin Nutr 2010;91:519-27.

8. Mattar SG. Lifting the unbearable weight of morbid obesity. Ann Surg 2008;247(1):28-9.

9. Finkelstein EA, Trogdon JG, Cohen JW, Dietz W. Annual medical spending attributable to obesity: payer-and service-specific estimates. Health Aff (Millwood) 2009;28(5):w822-31.

10. Hu FB, Willett WC, Li T, Stampfer MJ, Colditz GA, Manson JE. Adiposity as compared with physical activity in predicting mortality among women. N Engl J Med 2004;351(26):2694-703.

11. Gronbaek M, Deis A, Sørensen TI, et al. Influence of sex, age, body mass index, and smoking on alcohol intake and mortality. BMJ 1994;308(6924):302-6.

12. Baradel LA, Gillespie C, Kicklighter JR, Doucette MM, Penumetcha M, Blanck HM. Temporal changes in trying to lose weight and recommended weight- loss strategies among overweight and obese Americans, 1996-2003. Prev Med 2009;49(2-3): $158-64$.

13. Wing RR, Phelan S. Long-term weight loss maintenance. Am J Clin Nutr 2005;82(1 Suppl):222S-5S.

14. Centers for Disease Control and Prevention (CDC), National Center for Health Statistics (NCHS). National Health and Nutrition Examination Survey data. Hyattsville, MD: U.S. Department of Health and Human Services. Available at http://www. cdc.gov/nchs/about/major/nhanes/nh3data.htm. Accessed July 20, 2010.

15. National Institutes of Health. Clinical guidelines on the identification, evaluation, and treatment of overweight and obesity in adults: the evidence report. Obes Res 1998;6(suppl 2):51S-209S. [Published correction appears in Obes Res 1998;6:464.]

16. Ainsworth BE, Haskell WL, Leon AS, et al. Compendium of physical activities: classification of energy costs of human physical activities. Med Sci Sports Exerc 1993;25(1):71-80.

17. American College of Sports Medicine position stand. Exercise for patients with coronary artery disease. Med Sci Sports Exerc1994;26(3):i-v.

18. US Department of Health and Human Services, US Department of Agriculture. Dietary guidelines for Americans 2005: chapter 9, alcoholic beverages. Available at http:// www.health.gov/DIETARYGUIDELINES/dga2005/ document/html/chapter9.htm. Accessed July 20, 2010.

19. King DE, Mainous AG 3rd, Geesey ME. Turning back the clock: adopting a healthy lifestyle in middleage. Am J Med 2007;120:598-603. 
20. Reeves MJ, Rafferty AP. Healthy lifestyle characteristics among adults in the United States, 2000. Arch Intern Med 2005;165(8):854-7.

21. King NA, Hopkins M, Caudwell P, Stubbs RJ, Blundell JE. Beneficial effects of exercise: shifting the focus from body weight to other markers of health. Br J Sports Med 2009;43(12):924-7.

22. Sui X, LaMonte MJ, Laditka JN, et al. Cardiorespiratory fitness and adiposity as mortality predictors in older adults. JAMA 2007;298(21):2507-16.

23. Wee CC, McCarthy EP, Davis RB, Phillips RS. Physician counseling about exercise. JAMA 1999; 282(16):1583-8.

24. Yawn B, Goodwin MA, Zyzanski SJ, Stange KC. Time use during acute and chronic illness visits to a family physician. Fam Pract 2003;20(4):474-7.

25. Papadakis S, McDonald P, Mullen KA, Reid R, Skulsky K, Pipe A. Strategies to increase the delivery of smoking cessation treatments in primary care settings: a systematic review and meta-analysis. Prev Med 2010;51(3-4):199-213.

26. Steptoe A, Perkins-Porras L, McKay C, Rink E, Hilton S, Cappuccio FP. Behavioural counselling to increase consumption of fruit and vegetables in low income adults: randomised trial. BMJ 2003; 326(7394):855.
27. Wilk AI, Jensen NM, Havighurst TC. Meta-analysis of randomized control trials addressing brief interventions in heavy alcohol drinkers. J Gen Intern Med 1997;12(5):274-83.

28. Pinto BM, Goldstein MG, Ashba J, Sciamanna CN, Jette A. Randomized controlled trial of physical activity counseling for older primary care patients. Am J Prev Med 2005;29(4):247-55.

29. Cholesterol Treatment Trialists' (CTT) Collaborators. Efficacy and safety of cholesterol-lowering treatment: prospective meta-analysis of data from 90 056 participants in 14 randomized trials of statins. Lancet 2005;366:1267-78.

30. Fillenbaumv GG, Burchett BM, Blazer DG. Identifying a National Death Index match. Am J Epidemiol 2009;170(4):515-8.

31. Caspersen CJ, Pereira MA, Curran KM. Changes in physical activity patterns in the United States, by sex and cross-sectional age. Med Sci Sports Exerc 2000; 32(9):1601-9.

32. Jensen OM, Wahrendorf J, Rosenquist A, Geser A. The reliability of questionnaire-derived historical dietary information and temporal stability of food habits in individuals. Am J Epidemiol 1984;120(2):281-90. 